\title{
Propagación y tuberización in vitro de dos variedades de papa
}

\section{Propagation and in vitro tuberization of two varieties of potato}

\author{
Eyda Johanna Araque Barrera ${ }^{*}$ \\ María de los Angeles Bohórquez Quinteroa \\ José Estiben Pacheco Díaz \\ Lenny Yojana Correa Morac \\ Johan Sebastian Urquijo Ruiz \\ Sandra Liliana Castañeda Garzón e \\ José Constantino Pacheco Maldonadof
}

Fecha de Recepción: 02 - ago. - 2017

Fecha de Aceptación: 15 - dic. - 2017

\section{Resumen}

La investigación se realizó en el Laboratorio de Cultivo de Tejidos Vegetales de la Universidad Pedagógica y Tecnológica de Colombia con el propósito de conocer el comportamiento in vitro y evaluar una metodología para propagación de plántulas y producción de microtubérculos de dos variedades de papa (Solanum tuberosum L. ssp andígena) Diacol Capiro y Parda Pastusa, a partir de segmentos nodales obtenidos de tubérculos suministrados por el ICA, desinfectados con $\mathrm{NaOCl}$ al $10 \%$, multiplicados en medio MS y MS+ANA (0.02 mg L-1) y enraizados con ANA o AIB adicionados al medio de cultivo o aplicados en pulsos de 30 segundos. Posteriormente, segmentos uninodales micropropagados se cultivaron en medio para tuberización, observándose una mayor producción en MS suplementado con $2.5 \mathrm{mg} \mathrm{L}^{-1}$ de BA y $8 \%$ de sacarosa en las dos variedades. Los protocolos desarrollados en el presente estudio permitieron la obtención masiva de plántulas y la producción de microtubérculos de Diacol Capiro y Parda Pastusa; las plántulas y microtubérculos desarrollados pueden ser cultivados bajo condiciones controladas para la producción de semilla pre-básica.

Palabras clave: Diacol Capiro, microtuberización, Parda Pastusa, propagación, Solanum tuberosum.

a Estudiantes de Maestría en Ciencias Biológicas-UPTC, Laboratorio de Cultivo de Tejidos Vegetales BIOPLASMA-UPTC, Universidad Pedagógica y Tecnológica de Colombia. Avenida Central del Norte 39-115, Tunja, Colombia. *eyda.araque@ uptc.edu.co, mariadelosangeles.bohorquez@uptc.edu.co.*Autor de correspondencia.

b Estudiante de Maestría en Ciencias Agrarias. Universidad Nacional de Colombia. Carrera 30 No. 45-03, Edificio 500, Bogotá, D.C. - Colombia. jose.pacheco@uptc.edu.co.

c Estudiante de Pregrado en Ciencias Biológicas, Laboratorio de Cultivo de Tejidos Vegetales BIOPLASMA-UPTC, Universidad Pedagógica y Tecnológica de Colombia. Avenida Central del Norte 39-115, Tunja, Colombia. yojis.1812@gmail.com. d Ingeniero Agrónomo. Universidad Nacional de Colombia. Carrera 30 No. 45-03, Edificio 500, Bogotá, D.C. Colombia.jsurquijor@unal.edu.co.

e Investigador Master CORPOICA, Área temática de mejoramiento genético y material reproductivo. Centro de Investigación La Libertad. Kilómetro 15, vía Villavicencio-Puerto López, Meta. slcataneda@corpoica.org.

f Ph.D. Biología, Laboratorio de Cultivo de Tejidos Vegetales BIOPLASMA-UPTC, Universidad Pedagógica y Tecnológica de Colombia. Avenida Central del Norte 39-115, Tunja, Colombia. jocpach@gmail.com, 


\begin{abstract}
This study was conducted in the Laboratorio de Cultivo de Tejidos Vegetales of the Universidad Pedagógica $\mathrm{y}$ Tecnológica de Colombia with the purpose of acquiring knowledge on the behavior under in vitro conditions as to evaluate a methodology for the micropropagation of plantlets and the production of microtubers from two varieties of potato (Solanum tuberosum L. ssp andigena) Diacol Capiro and Parda Pastusa. The nodal segments provided by the ICA were disinfected with $10 \% \mathrm{NaOCl}$, Then cultured for multiplication in MS medium and MS+NAA $\left(0.02 \mathrm{mg} \mathrm{L}^{-1}\right)$. For the rooting process, NAA or IBA was added into the culture medium or applied in 30 seconds pulses. Subsequently, micropropagated uninodal segments were cultured in tuberization medium, showing an increase in production when supplemented with BA (2.5 $\left.\mathrm{mg} \mathrm{L}^{-1}\right)$ and with $8 \%$ saccharose in the two varieties. The protocols developed in this study allow a large number of micropropagated plantlets and production of microtubers of Diacol Capiro and Parda Pastusa; the plantlets and microtubers developed can be cultured under controlled conditions for the production of pre-basic seeds.
\end{abstract}

Keywords: Diacol Capiro, microtuberization, Parda Pastusa, propagation, Solanum tuberosum.

\section{INTRODUCCIÓN}

Evidencia arqueológica demuestra que la papa ha sido cultivada en la región Andina de América del Sur desde tiempos muy antiguos. Una vez que la agricultura se hizo más extensiva, la papa fue difundida a otras áreas geográficas, en donde se generaron variedades más adaptadas a cada lugar, mostrando cada cultivar nativo grandes diferencias en el tipo de hoja, color de flor y características de los tubérculos, tales como forma, color y sabor [1].

La papa, introducida de América a Europa en 1,580 , y posteriormente diseminada por el mundo, constituye uno de los cultivos de mayor importancia. A nivel mundial ocupa el tercer lugar como alimento para consumo humano, después del arroz y el trigo [2], es consumida como alimento básico en más de cuarenta países por sus propiedades funcionales, por su versatilidad y bajo costo en comparación con otros productos [3], llegando a más de 1,000 millones de consumidores, de los cuales, 500 millones de ese total son de los países en vía de desarrollo [4].

En Colombia el cultivo de papa involucra alrededor de unas 90,000 familias que habitan en las zonas rurales, donde siembran a 2014, aproximadamente unas 169,358 ha. y se cosechan 160,030 ha., que representan el $80 \%$ de las zonas altas de los departamentos de Cundinamarca (56.77 ha.), Boyacá (49.65 ha.), Nariño (36.99 ha.) y Antioquia (9.98 ha.) [5]. Es uno de los productos básicos de la seguridad alimentaria, siendo el producto agrícola de mayor consumo por su valor alimenticio rico en hidratos de carbono ( $75 \%$ de su materia seca), proteínas y/o aminoácidos, minerales (particularmente $\mathrm{K}$ y $\mathrm{Ca}$ ) y vitaminas $[3,6]$.

El departamento de Boyacá es un productor tradicional de papa (segundo a nivel nacional), con un área aproximada de cultivo de 37,370 ha., una producción de 829,150 ton. y un rendimiento promedio de 18.9 ton ha-1 [7]; no obstante, su cultivo se ha visto limitado, ya que la papa, como especie de propagación vegetativa, es susceptible a numerosas presiones bióticas (causadas por bacterias, hongos, virus, viroides y plagas) que tienen efecto dramático sobre el rendimiento y la calidad comercial del cultivo, pudiendo afectar también la distribución internacional de su germoplasma.

Lo anterior resalta la necesidad de implementar biotecnologías, como el cultivo de tejidos, que permitan el desarrollo de metodologías eficientes para la conservación, protección y propagación de diferentes recursos genéticos de papa que satisfagan adecuadamente los requerimientos propios del cultivo, así como los de producción para consumo y procesamiento.

En el país existen dos variedades comerciales importantes de papa, Diacol Capiro (DC) y Parda Pastusa (PP), que presentan limitantes relacionadas con la obtención de un producto de alta calidad, bajo rendimiento de producción, problemas fitosanitarios y características que no 
cumplen con las condiciones requeridas para la industria. Pese a que el cultivo de papa ha sido ampliamente estudiado, la producción de semilla de dichas variedades debe evolucionar hacia técnicas más eficientes, ya que esta es el medio a través del cual se lleva al agricultor todo el potencial genético de cultivares con características superiores [1, 8]. De acuerdo con Ranalli et al. [9], el potencial genético de una variedad o clon se conserva con tubérculos-semilla libres de virus, en los que su calidad fitosanitaria repercute en el rendimiento del cultivo, por lo que la producción de semilla prebásica es importante; esto quiere decir que las semillas de buena calidad garantizan mejores cosechas y son responsables de aumentos significativos en los rendimientos, por lo que su producción y usos son prioritarios para un país o una región productora.

Por lo anterior, el objetivo de la presente investigación es contribuir al conocimiento del comportamiento in vitro de las variedades, Diacol Capiro y Parda Pastusa, a partir del cultivo de segmentos nodales y posterior microtuberización como etapas necesarias para la producción de plantas madre y semilla libre de patógenos.

\section{MATERIALES Y MÉTODOS}

la investigación se desarrolló en el Laboratorio de Cultivo de Tejidos Vegetales BIOPLASMAUPTC de la Universidad Pedagógica y Tecnológica de Colombia, a partir de tubérculos-semilla certificados de las variedades de papa Diacol Capiro (DC) y Parda Pastusa (PP) suministrados por el Instituto Colombiano Agropecuario (ICA).

\subsection{Cultivo in vitro}

\subsubsection{Establecimiento, multiplicación y enraizamiento de segmentos nodales}

De tubérculos mantenidos en cuarto de crecimiento se escindieron brotes de 2 a $7 \mathrm{~cm}$. de longitud, que fueron sumergidos durante cinco minutos en agua destilada estéril más Tween 20, y luego, durante 30 segundos en etanol al 70\%. Finalmente se sumergieron en hipoclorito de sodio $(\mathrm{NaOCl})$ al $10 \%$ más Tween 20' durante 20 minutos y se enjuagaron tres veces con agua destilada estéril.
Segmentos uninodales asépticos de DC y PP (45 y 66 explantes por tratamiento, respectivamente) fueron cultivados en tubos de vidrio de $18 \mathrm{~cm}$. de longitud que contenían medio MS (Murashige y Skoog [10]) sin reguladores de crecimiento y MS suplementado con $0.02 \mathrm{mg} \mathrm{L}^{-1}$ de ácido naftalenacético (ANA) o $0.25 \mathrm{mg} \mathrm{L}^{-1} \mathrm{de}$ ácido giberélico $\left(\mathrm{GA}_{3}\right)$. Los explantes cultivados se incubaron a $24 \pm 1{ }^{\circ} \mathrm{C}$ con fotoperiodo de $16: 8 \mathrm{~h}$ utilizando lámparas fluorescentes (iluminación de $70-80 \mu \mathrm{mol} \mathrm{m} \mathrm{m}^{-2} \mathrm{~s}^{-1}$ ). A 15 y 30 días de cultivo se evaluó el porcentaje de tallos principales, de tallos secundarios, y el número promedio de segmentos nodales por tallo principal y tallo secundario, producidos por tratamiento; se determinó el medio más adecuado para multiplicación y se utilizó para el mantenimiento de cadenas proliferativas.

Para el desarrollo de raíces, segmentos nodales de DC y PP (15 explantes por tratamiento) provenientes de la etapa de multiplicación fueron cultivados en MS suplementado con 0.005, $0.01 \mathrm{y}$ $0.02 \mathrm{mg} \mathrm{L}^{-1}$ ANA y ácido indol-3-butírico (AIB) o sumergidos durante $30 \mathrm{seg}$. en $0.01,0.05$ y 0.1 mg L-1 de ANA y AIB y cultivados en MS sin reguladores de crecimiento. $\mathrm{Al}$ cabo de 20 días se evaluó el número promedio, longitud promedio y apariencia de las raíces.

\subsubsection{Microtuberización}

Microesquejes enraizados (15 repeticiones/ tratamiento) fueron cultivados en frascos de vidrio de $500 \mathrm{~mL}$. con medio MS semisólido sin reguladores de crecimiento (en oscuridad o fotoperiodo de 16 horas) o suplementado con 2.5, 5.0 y $12.0 \mathrm{mg} \mathrm{L}^{-1}$ de $6-\mathrm{N}$-bencil aminopurina (BA) ó 2.5 y $12.0 \mathrm{mg} \mathrm{L}^{-1}$ de Kinetina (Kin) o, medio MS líquido suplementado con $12 \mathrm{mg} \mathrm{L}^{-1}$ de BA y Kin. Todos los tratamientos fueron enriquecidos con $8 \%$ de sacarosa e incubados durante 90 días a $24 \pm 1{ }^{\circ} \mathrm{C}$. Los cultivos se incubaron durante 90 días. Los microtubérculos producidos fueron caracterizados morfométricamente (posición, diámetro longitudinal y transversal, peso en fresco y número de ojos) y posteriormente fueron germinados in vitro (en medio MS) o ex vitro (los microtubérculos fueron cultivados en una mezcla de tierra y arena en proporción 2:1, aclimatizados en el laboratorio y, posteriormente, bajo condiciones de invernadero). 


\subsubsection{Condiciones generales de cultivo}

Antes de adicionar el agar $\left(6.5 \mathrm{~g} \mathrm{~L}^{-1}\right)$, el $\mathrm{pH}$ de todos los medios se ajustó a 5.7 con $\mathrm{KOH}$ o $\mathrm{HCl} 1 \mathrm{~N}$ y se esterilizaron en autoclave a $15 \mathrm{psi}$ y $121^{\circ} \mathrm{C}$ durante 20 minutos.

\subsection{Cultivo ex vitro}

Las plántulas producidas in vitro fueron transferidas a bolsas negras de polietileno de $9 \mathrm{x}$ $18 \mathrm{~cm}$, con sustrato compuesto por tierra:arena en proporción $2: 1$ y mantenidos en invernadero con riego diario por aspersión manual durante 8 días y posteriormente cada cuarto día.

\subsection{Análisis estadístico}

Los datos obtenidos fueron procesados mediante el software estadístico PASW Statistics 18. Versión 18.0.0 (30-jul-2009) (SPSS, 2009) y Excel 2013 y, analizados con la prueba Chicuadrado de bondad de ajuste con un nivel de confianza del $95 \%$ para la fase de multiplicación y microtuberización. Para la etapa de enraizamiento y morfometría de tubérculos, se realizó un análisis de varianza univariado (ANOVA) y una vez se determinaron diferencias significativas se aplicó la prueba de comparación múltiple Diferencia Mínima Significativa DMS (LSD).

\section{RESULTADOS Y DISCUSIÓN}

\subsection{Establecimiento y multiplicación de segmentos nodales.}

El protocolo de desinfección aplicado permitió obtener $100 \%$ de explantes superficialmente asépticos.

El crecimiento y desarrollo de las yemas de los segmentos nodales utilizados para el establecimiento in vitro de las variedades Diacol Capiro y Parda Pastusa mostraron dos comportamientos: desarrollo de tallos principales (tallos producidos a partir del entrenudo basal o primera yema) y desarrollo de tallos secundarios (tallos producidos a partir del segundo entrenudo o desarrollados de yemas medias y superiores), observándose, en los primeros, crecimiento uniforme de tallos con un grosor mínimo de $2 \mathrm{~mm}$ de diámetro, constituyendo explantes óptimos para el establecimiento de cadenas de proliferación. En tanto, en los tallos secundarios, el grosor del tallo fue, en general, menor de 2 $\mathrm{mm}$ de diámetro, reduciéndose a medida que estos se desarrollaban en segmentos cercanos al ápice (yemas medias y superiores), siendo explantes no aptos para multiplicar, exceptuando su primer segmento nodal. Para Rishi et al. [11] estos parámetros son de gran importancia para el estudio de la tasa de crecimiento, ya que las plántulas robustas tienen un mayor número de nodos, por lo que son capaces de generar más propágulos adecuados para multiplicación; además, resalta que según estudios realizados en las variedades de papa Kufri Giriraj, Kufri Girdhari, Kufri Himalini y Kufri Himsona, se ha demostrado que los nodos desarrollados a lo largo del vástago responden de manera diferente a través de cultivos consecutivos.

Pese a que la morfología de los explantes de las dos variedades fue similar, los datos registrados en los diferentes tratamientos para multiplicación muestran, según la prueba chicuadrado, que existen diferencias significativas en la producción de tallos principales $(\mathrm{p}=0.0459$; $\left.\mathrm{p}<0.05 ; \mathrm{chi}^{2}=6.1622\right)(\mathrm{p}=8.8966 \mathrm{E}-23 ; \mathrm{p}<$ $0.05 ;$ chi $\left.^{2}=101.5476\right)$, número de segmentos nodales de tallos principales ( $\mathrm{p}=1.8004 \mathrm{E}-16 ; \mathrm{p}<$ $\left.0.05 ; \mathrm{chi}^{2}=72.5067\right)\left(\mathrm{p}=0.0004 ; \mathrm{p}<0.05 ; \mathrm{chi}^{2}\right.$ $=15.3037)$, tallos secundarios $(\mathrm{p}=7.722 \mathrm{E}-15 ; \mathrm{p}$ $\left.<0.05 ; \mathrm{chi}^{2}=64.9894\right)(\mathrm{p}=0.0003 ; \mathrm{p}<0.05$; chi $\left.^{2}=16.2222\right)$, y número de segmentos nodales de tallos secundarios $(\mathrm{p}=9.037 \mathrm{E}-94 ; \mathrm{p}<0.05$; $\left.\mathrm{chi}^{2}=428.4834\right)\left(\mathrm{p}=1.523 \mathrm{E}-08 ; \mathrm{p}<0.05 ; \mathrm{chi}^{2}=\right.$ 36.0), para PP y DC, respectivamente.

En PP, el tratamiento en el que se cuantificó los valores más altos para las variables consideradas fue MS $+0.02 \mathrm{mg} \mathrm{L}^{-1}$ de ANA con 88 tallos principales (39.2 \%) (1.35 tallos promedio/ explante) con 419 nodos (40.1\%) (4.19 nodos promedio/explante) y 98 tallos secundarios (34.4\%) (1.5 tallos promedio/explante) con 93 nodos (17.2\%) (1.43 nodos promedio/explante). Mientras que para Diacol Capiro fueron los medios $\mathrm{MS}+0.25 \mathrm{mg} \mathrm{L}^{-1}$ de $\mathrm{GA}_{3}$, con 219 tallos principales (46.3\%) (5.09 tallos promedio/ explante) con 219 nodos (31.4\%) (5.09 nodos promedio/explante) y 34 tallos secundarios (42 $\%)$ ( 0.79 tallos promedio/explante) con 72 nodos (44.4\%) (1.67 nodos promedio/explante) y MS, con 55 tallos principales (11.6\%) (1.31 tallos 
promedio/explante) con 280 nodos $(40.1 \%)(6.67$ nodos promedio/explante) y 37 tallos secundarios (45.7\%) (0.88 tallos promedio/explante) con 72 nodos (44.4\%) (1.71 nodos promedio/explante).

Los medios mencionados para cada variedad, promovieron el desarrollo de las yemas preexistentes, su composición nutricional $\mathrm{y}$ hormonal rompió la latencia del brote axilar de forma similar a los resultados obtenidos para papa por Mejía et al. [12] (papa ratona: Oxalis tuberosa Molina, S/A) y Pruski [13] (Solanum tuberosum L.) en las que el medio MS suplementado con ANA (1 mg L-1) y MS sin reguladores, tuvo efecto positivo, produciendo brotes de apariencia uniforme, vigorosos, de mayor grosor y longitud promedio, favoreciendo la supervivencia $y$ tasa de desarrollo de los inóculos, debido, principalmente, a las concentraciones de iones de potasio, amonio e inositol, junto con la cantidad adecuada de ANA (ya que concentraciones excesivas o altas de ANA, inhiben la brotación de yemas en diferentes especies); es decir que, tanto los componentes del medio de cultivo como el tipo de regulador de crecimiento empleado, repercutieron directamente en el suministro de nutrientes y sustancias necesarias para el desarrollo de tejidos u órganos de las variedades DC y PP.
El alto número de segmentos nodales que se recuperaron en los medios ensayados en la fase de multiplicación para las dos variedades fue efectivo para el mantenimiento de las cadenas de proliferación, lo que ratifica que, aunque la papa es multiplicada usando diferentes técnicas in vitro, los segmentos nodales continúan siendo los explantes comúnmente utilizados por su eficiencia y rápido desarrollo, tal como fue indicado por Danci [14], Millam [15], Pruski [13] y Rai et al. [16].

\subsection{Enraizamiento de brotes}

Después de siete días de cultivo en los medios para enraizamiento, en la mayoría de los explantes de PP y DC se observaron primordios radicales y después 20 días, en todos los medios ensayados, se observó crecimiento y desarrollo de raíces en las dos variedades en todos los medios ensayados, excepto en el tratamiento de pulsos con $0.05 \mathrm{mg} \mathrm{L}^{-1}$ de ANA para la variedad DC (Tabla 1), semejante a lo reportado para papa ratona [12] en la cual, la fase de enraizamiento fue exitosa, ya que a 15 días de cultivo el $80 \%$ de todos los explantes cultivados in vitro enraizaron de manera abundante y vigorosa.

Tabla 1. Promedios de número y longitud de raices por brote, cuantificados en MS suplementado con diferentes concentraciones de ANA y AIB (mg L L-1). *P: Pulsos. **Letras distintas en la misma columna indican diferencias entre tratamientos según Prueba LSD (nivel de confianza del $95 \%$ ).

ANA: ácido naftalenacético; AIB: ácido indol-3-butírico.

\begin{tabular}{lrrrr}
\hline & \multicolumn{2}{c}{ Parda Pastusa } & \multicolumn{2}{c}{ Diacol Capiro } \\
\hline Tratamiento & $\bar{x}$ de raíces & Longitud $\bar{x}(\mathbf{c m})$ & $\bar{x}$ de raíces & Longitud $\bar{x}(\mathbf{c m})$ \\
MS & $2.13 \pm 1.75^{\mathrm{cde}}$ & $3.53 \pm 1.49 \mathrm{de}$ & $4.13 \pm 2.70^{\mathrm{bc}}$ & $6.57 \pm 1.97 \mathrm{bcd}$ \\
0.005 ANA & $4.07 \pm 1.98 \mathrm{ab}$ & $8.13 \pm 2.37 \mathrm{ab}$ & $2.86 \pm 1.88^{\mathrm{c}}$ & $7.43 \pm 2.53^{\mathrm{ab}}$ \\
0.01 ANA & $2.53 \pm 2.34 \mathrm{bcde}$ & $6.17 \pm 2.35^{\mathrm{abc}}$ & $3.47 \pm 1.25_{\mathrm{bc}}$ & $7.13 \pm 1.19 \mathrm{abc}$ \\
0.02 ANA & $2.13 \pm 1.72^{\mathrm{cde}}$ & $4.73 \pm 1.99 \mathrm{cde}$ & $3.60 \pm 1.84 \mathrm{bc}$ & $7.00 \pm 2.27 \mathrm{bc}$ \\
0.005 AIB & $2.53 \pm 1.53 \mathrm{bcde}$ & $5.73 \pm 2.04 \mathrm{bcd}$ & $5.15 \pm 2.67 \mathrm{~b}$ & $7.08 \pm 1.50^{\mathrm{abc}}$ \\
0.01 AIB & $2.80 \pm 1.88^{\mathrm{bcd}}$ & $5.37 \pm 1.97 \mathrm{cde}$ & $3.54 \pm 2.92^{\mathrm{bc}}$ & $6.85 \pm 1.24 \mathrm{bc}$ \\
0.02 AIB & $3.13 \pm 2.43_{\mathrm{bcd}}$ & $5.07 \pm 1.68^{\mathrm{cde}}$ & $5.09 \pm 2.63 \mathrm{~b}$ & $6.55 \pm 2.02^{\mathrm{bcd}}$ \\
P 0.1 AIB & $2.40 \pm 3.13^{\mathrm{cde}}$ & $1.06 \pm 1.27 \mathrm{fg}$ & $7.08 \pm 3.09 \mathrm{a}$ & $5.46 \pm 3.45^{\mathrm{cd}}$ \\
P 0.01 AIB & $3.60 \pm 2.54 \mathrm{abc}$ & $6.55 \pm 3.15^{\mathrm{abc}}$ & $3.80 \pm 1.48 \mathrm{bc}$ & $8.20 \pm 1.93^{\mathrm{ab}}$ \\
P 0.05 AIB & $4.87 \pm 3.36^{\mathrm{a}}$ & $8.20 \pm 6.32^{\mathrm{a}}$ & $4.67 \pm 2.44 \mathrm{bc}$ & $7.05 \pm 2.92^{\mathrm{abc}}$
\end{tabular}




\begin{tabular}{lrrrr} 
P 0.1 ANA & $0.93 \pm 0.00 \mathrm{e}$ & $0.58 \pm 0.37 \mathrm{~g}$ & $3.00 \pm 0.00^{\mathrm{bc}}$ & $2.00 \pm 0.00^{\mathrm{d}}$ \\
P 0.01 ANA & $1.60 \pm 2.07 \mathrm{de}$ & $3.12 \pm 3.75^{\mathrm{ef}}$ & $4.78 \pm 1.64 \mathrm{bc}$ & $8.89 \pm 1.45^{\mathrm{a}}$ \\
P 0,05 ANA & $1.00 \pm 0.00 \mathrm{e}$ & $0.03 \pm 0.13 \mathrm{~g}$ & $0.00 \pm 0.00^{\mathrm{d}}$ & $0.00 \pm 0.00 \mathrm{e}$ \\
\hline
\end{tabular}

Según el análisis de varianza y la prueba LSD, existen diferencias significativas entre los tratamientos para las variables número promedio y longitud promedio de raíces en las dos variedades de papa, distinguiéndose los tratamientos de pulsos con $0.05 \mathrm{mg} \mathrm{L}^{-1} \mathrm{de}$ AIB (5 raíces de $8 \mathrm{~cm}$. de longitud) y medio $\mathrm{MS}+0.005$ $\mathrm{mg} \mathrm{L}^{-1}$ de ANA (4 raíces de $8 \mathrm{~cm}$. de longitud) y, medio MS $+0.005 \mathrm{mg} \mathrm{L}^{-1}$ de AIB (5 raíces de 7 cm. de longitud) y MS $+0.02 \mathrm{mg} \mathrm{L}^{-1}$ de AIB (5 raíces de $6 \mathrm{~cm}$. de longitud) como aquellos que indujeron los mejores promedios de número y longitud de raíces para PP y DC, respectivamente; no obstante, para cada variedad, se observó un comportamiento semejante entre tratamientos, de tal forma que se identificaron 5 y 7 , y 4 y 5 grupos para los promedios de raíces y longitud, para PP y DC, respectivamente, lo cual sugiere que los tratamientos con valores mayores al tratamiento control (PP: 2 raíces de $3.5 \mathrm{~cm}$. de longitud, y DC: 4 raíces de $7 \mathrm{~cm}$. de longitud), estimulan la formación de raíces con mejores características.

Según Arellano et al. [1] es de gran importancia que el enraizamiento de las vitroplantas sea inducido dentro del medio de cultivo, pues de ello depende en gran medida que se obtengan altas tasas de viabilidad en la siguiente fase; aunque las raíces formadas en dicha etapa no son $100 \%$ funcionales para la asimilación de nutrientes, sí aseguran un buen anclaje en el sustrato cuando se establecen en invernadero, es decir que, un buen patrón de enraizamiento asegura un mejor establecimiento de las plantas en invernadero o campo aumentando la supervivencia, tal como lo ha reportado Rai et al. [16] y Srivastava et al. [17] en las variedades de papa Kufri Jyoti, Kufri Megha, Kufri Giriraj, Kufri Girdhari, Kufri Himalini y Kufri Himsona.

Teniendo en cuenta que en el tratamiento control se observó desarrollo radical, y aunque Arellano et al. [1] indican que en papa no se requieren reguladores de crecimiento para inducir este proceso, pero sí condiciones mixotróficas que lo favorezcan, como regular la concentración de sacarosa del medio en el último subcultivo y controlar el fotoperíodo, la estimulación con auxinas indujo mejores resultados en cantidad y apariencia del sistema radical. Cotes y Ñústez [18] sugieren que estas respuestas se pueden atribuir, fisiológicamente, a que los segmentos nodales tienen una mayor concentración de hormonas (auxinas principalmente) y fotoasimilados, ya que poseen meristemos apicales en crecimiento activo y al poseer mayores concentraciones de hormonas $\mathrm{y}$ fotoasimilados manifiestan una mayor facilidad para enraizar.

\subsection{Microtuberización}

Todos los tratamiento ensayados tuvieron efecto positivo sobre la tuberización in vitro de las dos variedades de papa, excepto el tratamiento MS (semisólido y líquido) suplementado con 12 $\mathrm{mg} \mathrm{L}^{-1}$ de BA para la variedad DC (Fig. 1). Los explantes desarrollaron microtallos con varios segmentos nodales, los cuales, progresivamente, se fueron engrosando (Fig. 2A, E) y formaron microtubérculos basales (Fig. 2B, F) y aéreos (Fig. 2C, G) de color blanquesino, verde y/o café (Fig. 2D, H).

Figura 1. Media porcentual de microtuberización de las variedades de papa Diacol Capiro y Parda Pastusa, cuantificada en medio MS suplementado con diferentes concentraciones de BA, AIB o KIN (mg L $\left.L^{-1}\right)$. *L: líquido.

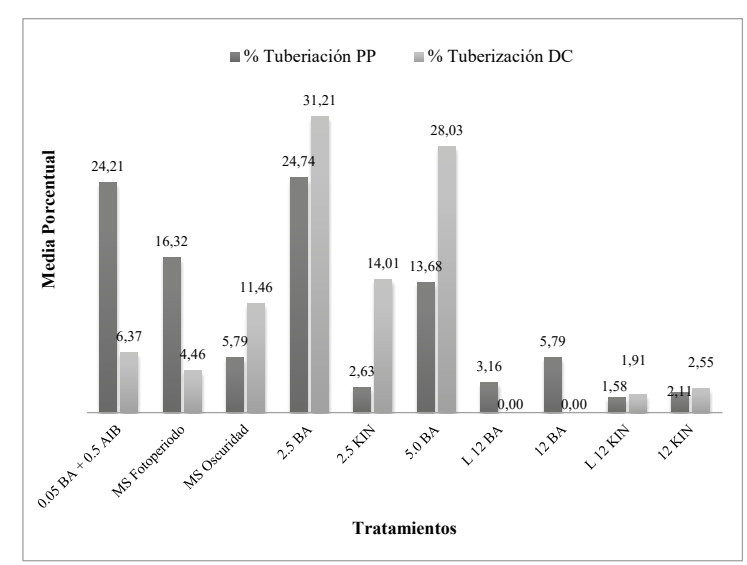


Figura 2. Microtuberización de Solanum tuberosum L. ssp andígena, Variedad Parda Pastusa A. Engrosamiento de tallo. B. Microtubérculos basales. C. Microtubérculos aéreos. D. Explante con microtubérculos basales y aéreos. Variedad Diacol Capiro E. Engrosamiento de tallo. F. Microtubérculos basales. G. Microtubérculos aéreos. H. Explante con microtubérculos basales y aéreos.
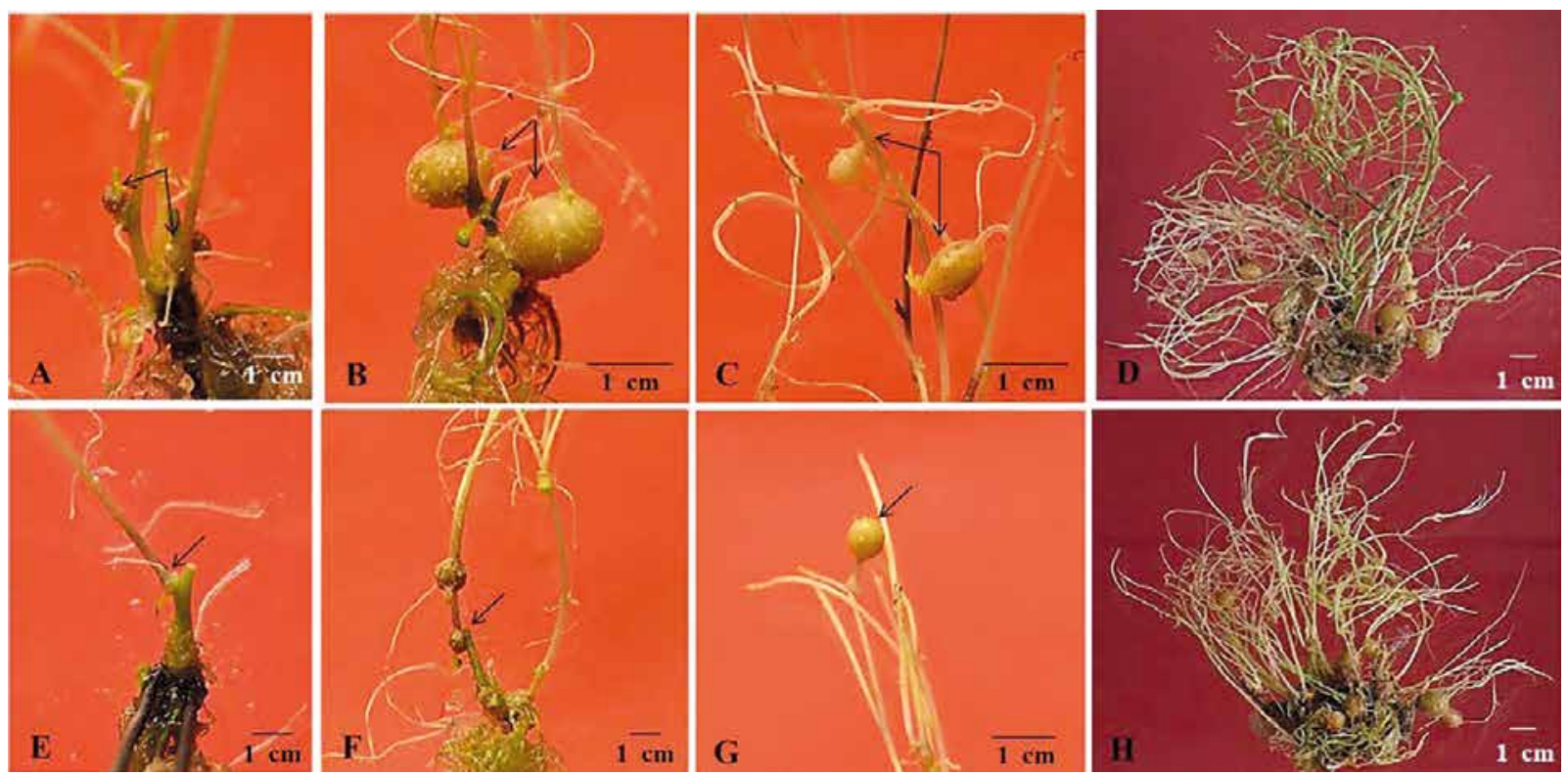

Según la prueba chi-cuadrado $(\mathrm{p}=5.77 \mathrm{E}-57$; $\left.\mathrm{p}<0.05 ; \mathrm{chi}^{2}=322.1066\right)$ existen diferencias significativas entre los tratamientos aplicados, siendo el medio $\mathrm{MS}+2.5 \mathrm{mg} \mathrm{L}^{-1}$ de BA el que registró el mayor porcentaje de tuberización en las dos variedades, con el 13.54 y $14.12 \%$ del total de tubérculos para PP y DC, respectivamente; estos resultados son semejantes a los reportados por Aslam et al. [19], Lugo et al. [20], Hussain et al. [21], Azzopardi [22], entre otros, para las variedades Desiree, Cardinal, Alfa, Andinita y Kennebec, en tratamientos con $3-14 \mathrm{mg} \mathrm{L}^{-1}$ de BA, por Arellano et al. [1] para las variedades Atlantic, Gigant, Mondial, Alfa, Felsina, Vivaldi y Caesar en el tratamiento con $5 \mathrm{mg} \mathrm{L}^{-1}$ de BA y $500 \mathrm{mg} \mathrm{L}^{-1}$ de Cloruro de Clorocolina (CCC) y, por Montoya et al. [23] para Diacol Capiro en el tratamiento con $1 \mathrm{mg} \mathrm{L}^{-1}$ de BA.

Los medios que estimularon la formación de mayor cantidad de microtubérculos por explante, en orden descendente fueron: $\mathrm{MS}+2.5 \mathrm{mg} \mathrm{L}-1$ de BA (24\%: 47 microtubérculos), MS + 0.05 mg L-1 de BA + $0.5 \mathrm{mg} \mathrm{L}^{-1}$ de AIB (24\%: 46 microtubérculos), MS fotoperiodo (16\%: 31 microtubérculos), MS + $5 \mathrm{mg} \mathrm{L}^{-1}$ de BA (14\%: 26 microtubérculos) para Parda Pastusa, y MS + 2.5 mg L-1 de BA (31\%: 49 microtubérculos), MS + $5 \mathrm{mg} \mathrm{L}^{-1}$ de BA (28\%: 26 microtubérculos), MS
+ $2.5 \mathrm{mg} \mathrm{L}^{-1}$ de KIN (14 \%: 22 microtubérculos), MS oscuridad (11\%: 18 microtubérculos) para Diacol Capiro (Fig. 1).

Según Aslam y Iqbal [24] y Aslam et al. [25] la formación y desarrollo de microtubérculos se debe, principalmente, a la combinación de citoquininas y azúcares en el medio, ya que las citoquininas estimulan el metabolismo enzimático creando una fuerte depresión metabólica e inician la transición de yemas axilares a tubérculos, y la sacarosa proporciona una fuente de carbono de fácil asimilación que produce síntesis ininterrumpida de almidón debido al alto potencial osmótico proporcionado por el exceso de sacarosa $\mathrm{y}$, finalmente, la formación de microtubérculos. Donnelly et al. [26] y Diémé et al. [4] respaldan lo anterior, sosteniendo que la microtuberización requiere una importante provisión de sacarosa y reguladores de crecimiento, siendo más precoz cuando el medio se enriquece con citoquininas tales como BA y CCC y una cantidad de $8 \%$ de sacarosa.

Además, es de resaltar que las condiciones de iluminación (continua, fotoperiodo y oscuridad) afectan notoriamente la inducción de tuberización. Donnelly et al. [26] han demostrado que la exposición a día corto u oscuridad, incrementa 
la eficiencia en la microtuberización, tal como se observó en el presente estudio para la PP y DC.

Después de 90 días de incubación bajo condiciones de tuberización, los tratamientos aplicados mostraron un efecto estadísticamente significativo $(\mathrm{p}=0)$ sobre las características morfológicas de los microtubérculos producidos en las dos variedades; no obstante, la posición del microtubérculo (basal o aéreo) tuvo gran influencia sobre dichas características ya que los que se desarrollaron en la base del primer segmento nodal registraron los valores más altos para las variables consideradas, conforme a lo establecido por Hoque [27] para la variedad Diamante, en la cual se produjo mayor número de tubérculos con las mejores características en la zona basal y media de los explantes.

Los tratamientos en los cuales se observó mayor crecimiento y desarrollo de microtubérculos fueron $12 \mathrm{mg} \mathrm{L}^{-1}$ de KIN (tubérculos promedio de $160.18 \mathrm{mg}$., $4.26 * 3.80 \mathrm{~mm}$. de diámetro y 3.5 ojos) y $2.5 \mathrm{mg} \mathrm{L}^{-1}$ de BA (tubérculos promedio de $143.09 \mathrm{mg}$., $6.85 * 5.28 \mathrm{~mm}$. de diámetro y 4.3 ojos) para PP y, MS oscuridad (tubérculos promedio de $113.58 \mathrm{mg}$., $5.64 * 4.69 \mathrm{~mm}$. de diámetro y 5 ojos) y suplementado con $2.5 \mathrm{mg}$ $\mathrm{L}^{-1}$ de KIN (tubérculos promedio de 123.90 mg., $5.97 * 4.32 \mathrm{~mm}$. de diámetro y 4.3 ojos) y BA (tubérculos promedio de $97 \mathrm{mg}$., 5.43*4.08 mm. de diámetro y 4.3 ojos) para DC. Resultados similares se obtuvieron en la variedad Diamante en concentración $4 \mathrm{mg} \mathrm{L}^{-1}$ de KIN [27], en la variedad Alfa en concentración de $2.5 \mathrm{mg} \mathrm{L}^{-1} \mathrm{de}$ KIN [28] y $8 \%$ sacarosa [29] y en la variedad Diacol Capiro, clon Atlantic, Andinita y Kennebec en concentraciones de $8 \%$ de sacarosa [20, 23, 30], entre otras. No obstante, Donnelly et al. [26], proponen que los reguladores de crecimiento (BAP y KIN) pueden inducir tubérculos in vitro de papa pero que en la mayoría de los casos el efecto de estos es dependiente del genotipo.

Algunos autores advierten que las bajas densidades de cultivo aumentan el desarrollo morfológico de los tubérculos, ya que se reduce la competencia por nutrientes; además, la proximidad del explante al medio aumenta su transporte y utilización, otorgándole mejores características a los tubérculos formados en la yema basal. Al respecto, Aslam et al. [25] mencionan que obtener microtubérculos de mayor peso y tamaño permite aprovechar mejor las ventajas de estos, porque pueden ser almacenados o llevados directamente a campo sin un proceso previo de aclimatización. La mayoría de autores concuerda con que la producción de tubérculossemillas de papa debe iniciarse con material de la más alta calidad sanitaria, por lo tanto es necesario disponer de núcleos iniciales generados de plantas in vitro o de plantas que provengan de un programa de multiplicación clonal, ya que a partir de estas plantas o de sus descendientes se pueden producir muchas más por multiplicación acelerada, tal como queda planteado y descrito en la presente investigación. Además, en varios trabajos de cultivo de tejidos con papa, se ha planteado que utilizar tuberculillos para iniciar cultivos in vitro presenta ciertas ventajas sobre los explantes nodales, pues producen plantas en la mitad del tiempo que le tomaría a los explantes nodales y el proceso no depende de la presencia de sacarosa en el medio.

Finalmente se debe resaltar que los tratamientos en los cuales los microtubérculos presentaron las mejores características no corresponden a los que registran mayor tuberización, excepto el medio MS suplementado con $2.5 \mathrm{mg} \mathrm{L}^{-1}$ de BA, razón por la cual se establece que es el tratamiento más adecuado para microtuberización en las variedades PP y DC, de manera semejante a lo reportado para Diacol Capiro, Andinita y Kennebec, en las cuales el tratamiento con 1.0 $\mathrm{mg} \mathrm{L}^{-1}$ y $12 \mathrm{mg} \mathrm{L}^{-1}$ de BA $+8 \%$ sacarosa, indujo tuberización y además favoreció el tamaño, peso y proliferación de los microtubérculos y de los tallos [20, 23].

\subsection{Cultivo ex vitro:}

La composición del sustrato utilizado favoreció el desarrollo de las plántulas micropropagadas, las cuales presentaron apariencia vigorosa y buen crecimiento y desarrollo caulinar y radical. Se registró una viabilidad del 93 y $95 \%$ para la variedad PP y DC, respectivamente.

El protocolo permitió obtener un número suficiente de plantas madre homogéneas para la producción de semilla pre-básica.

De acuerdo con los resultados obtenidos para 
las variedades PP y DC, se indica que las respuestas observadas durante los ensayos de micropropagación y tuberización, están fuertemente influenciadas por el genotipo, tipo de explante y la edad fisiológica de los explantes utilizados; por tanto, es imperativo conocer el comportamiento in vitro particular de cada variedad antes de emprender programas de multiplicación a gran escala.

\section{CONCLUSIONES}

Teniendo en cuenta las características morfológicas que presentan los explantes de PP y DC durante las diferentes etapas de micropropagación así como el análisis estadístico de los resultados obtenidos en cada una de ellas se establece que los medios que permiten la obtención de explantes adecuados para multiplicación y mantenimiento de cadenas proliferativas son $\mathrm{MS}+0,02 \mathrm{mg} \mathrm{L}^{-1}$ de ANA y MS sin reguladores, respectivamente. Así mismo, los tratamientos que garantizan el desarrollo de un sistema radical adecuado son los realizados con $0.05 \mathrm{mg} \mathrm{L}^{-1}$ de AIB aplicado en pulsos y/o medio MS $+0.005 \mathrm{mg} \mathrm{L}^{-1}$ de ANA para PP y, $0.005 \mathrm{mg} \mathrm{L}^{-1}$ de AIB aplicado y/o medio MS + $0.02 \mathrm{mg} \mathrm{L}^{-1}$ de AIB para DC.

La mayor tuberización in vitro se alcanza en MS suplementado con $2.5 \mathrm{mg} \mathrm{L}^{-1}$ de BA y $8 \%$ de sacarosa, registrándose un total de 47 microtubérculos con peso promedio de 143.09 mg. y $6.85 * 5.28 \mathrm{~mm}$. de diámetro en PP y, un total de 49 microtubérculos con peso promedio de $97 \mathrm{mg}$. y 5.43*4.08 mm. de diámetro para DC.

Los protocolos desarrollados en la presente investigación pueden ser empleados para la multiplicación de material vegetal y producción de microtubérculos de papa variedades Parda Pastusa y Diacol Capiro de alta sanidad. Las plántulas y microtubérculos desarrollados pueden ser cultivados bajo condiciones controladas para la producción de semilla pre-básica, la cual, después de algunos ciclos de multiplicación puede ser entregada a los agricultores.

\section{AGRADECIMIENTOS}

Al personal del Laboratorio de Cultivo de Tejidos Vegetales BIOPLASMA-UPTC, por el apoyo durante la ejecución y desarrollo de esta investigación, la cual fue financiada por el programa Jóvenes Investigadores UPTC-DIN Acuerdo 010 de 2013, así como a la Dirección de Investigaciones, DIN, de la Universidad Pedagógica y Tecnológica de Colombia.

\section{REFERENCIAS}

[1] M. Arellano, M. García, E. Villavicencio, y S. García, Producción de plántulas y semilla prebásica de variedades comerciales de papa libres de enfermedades, Folleto Técnico Núm. 41. 1a. ed. Instituto Nacional de Investigaciones Forestales, Agrícolas y Pecuarias, Centro de Investigación Regional Noreste, Campo Experimental Saltillo, Saltillo, México, 2010. ISBN: 978-607-425-301-6.

[2] T. Gavrilenko, O. Antonova, A. Shuvalova, E. Krylova, N. Alpatyeva, D. Spooner, and L. Novikova, "Genetic diversity and origin of cultivated potatoes based on plastid microsatellite polymorphism", Genet. Resour. Crop Evol., vol. 60(7), pp. 19972015, 2013.

[3] M. Otálora, M. López, L. Mancilla. "Caracterización fisicoquímica, funcional, microbiológica, sensorial y de estabilidad de la harina de papa (Solanum tuberosum) para puré instantáneo", Ciencia en Desarrollo, vol. 3(2), pp. 107-128, 2011.

[4] A. Diémé, M. Nahr, E. Codjo, and M. Ourèye, "Residual effects of sucrose and hormonal treatments of the tuberization medium on in vitro germination of potato (Solanum tuberosum L.) microtubers". AJPS, vol. 4, pp. 1872-1878, 2013. 
[5] Agronet, “Área sembrada, área cosechada, producción y rendimiento del cultivo de papa en Colombia" [online], Ministerio de Agricultura de Colombia. 2016. Disponible en: http://www.agronet.gov.co/Documents/ Papa.pdf\#search=producci $\% \mathrm{C} 3 \% \mathrm{~B} 3 \mathrm{n} \% 20$ de\%20papa.

[6] D. Rodríguez, y L. Ramírez, "La agroindustria de la papa criolla en Colombia. Situación actual y retos para su desarrollo", Gestión y Sociedad, vol. 4(2) pp. 17-30, 2011.

[7] C. Ruiz, D. Henao, M. Lozano, L. Colorado, H. Mora, J. Velandia et al. Plan Estratégico Departamental de Ciencia, Tecnología e Innovación de Boyacá. Boyacá 2022: La ciencia, la tecnología y la innovación al servicio del desarrollo regional. Primera edición. Departamento Administrativo de Ciencia, Tecnología e Innovación, Colciencias, Gobernación de Boyacá, Observatorio Colombiano de Ciencia y Tecnología - OCyT. Bogotá, Colombia. 2012. ISBN: 978-958-57775-1-4.

[8] J. Velásquez, Producción de tubérculosemillas de papa en la estación experimental Santa Catalina del INIAP y su relación con el sector semillero nacional. Estación Experimental Santa Catalina, INIAP. Ecuador. pp. 1-8. 2014.

[9] P. Ranalli, F. Bassi, A. Ruaro, P. del Re, M. Di. Candilo, and A. Mandolino, "Microtuber and minituber production and field performance compared with normal tubers" Potato Research, vol. 37, pp. 383391, 1994.

[10] T. Murashige, F. Skoog, "A revised medium for rapid growth and bio-assays with Tobacco tissue cultures", Physiol. Plant, vol. 15(3), pp. 473-497, 1962.

[11] R. Rishi, L. Diengdoh, A. Srivastava, and T. Bag, "Efficiency of different nodal segments for potato micro-propagation", Environment and Ecology, vol. 30(3), pp. 594-597, 2012.
[12] J. Mejía, S. González, R. Mora, y J. Rodríguez, "Propagación in vitro de papa ratona (Oxalis tuberosa Mol.)", Revista Chapingo Serie Horticultura, vol. 12(2), pp. 231-237, 2006.

[13] K. Pruski, "In vitro multiplication through nodal cuttings", Potato Research, vol. 50, pp. 293-296, 2008.

[14] Danci, O. "Studies regarding the elaboration of an optimum micro-propagation protocol for potato cultivar recalcitrant to in vitro cultures", RJAS, vol. 39(2), pp. 577-580, 2007.

[15] S. Millam, "Development in transgenic biology and the genetic engineering of useful traits", in Potato biology and biotechnology, D. Vreugdenhil, D. Elsevier, Amsterdam, Netherlands, 2007, pp. 669-686.

[16] R. Rai, L. Diengdoh, A. Srivastava, and T. Bag, "Efficiency of different nodal segments for potato micropropagation", Environment and Ecology, vol. 30(3), pp. 594-597, 2012.

[17] A. Srivastava, L. Diengdoh, R. Rai, T. Bag, and $\mathrm{B}$. Singh "In vitro micropropagation and micro-tuberization potential of selected potato varieties", Indian Journal of Hill Farming, vol. 25(2), pp. 14-17, 2012.

[18] J. Cotes, y C. Nústez, "Evaluación de dos tipos de esquejes en la producción de semilla prebásica de papa criolla (Solanum phureja Juz et. Buk) Variedad "Yema de Huevo". Agronomía Colombiana, vol. 18(1-2), pp. 7-13, 2001.

[19] A. Aslam, A. Ali, N. Huma, A. Saleem and J. Iqbal, "Effect of interaction of 6-benzyl aminopurine (BA) and sucrose for efficient microtuberization of two elite potato (Solanum tuberosum L.) cultivars, Desiree and Cardinal", $A J B$, vol. 10(59), pp. 1273812744, 2011.

[20] J. Lugo, N. Mogollón, Z. Rodríguez, y J. Díaz "Efecto del intercambio gaseoso sobre el crecimiento y tuberización de vitroplantas 
de papa", Rev. Fac. Agron. (LUZ), vol. 26, pp. 325-339, 2009.

[21] I. Hussain, Z. Chaudhry, A. Muhammad, R. Asghar, S. Saqlan, and H. Rashid, "Effect chlorocholine chloride, sucrose and bap on in vitro tuberization in potato (Solanum tuberosum L. cv. Cardinal)", Pakistan J. Bot., vol. 38(2), pp. 275-282, 2006.

[22] N. Azzopardi, Micropropagation of Solanum tuberosum varieties (Alpha and Desiree) for the production of seed tubers, Institute of Agriculture, University of Malta, Malta, República de Malta, 1997.

[23] N. Mon Montoya, D. Castro, J. Díaz, y D. Ríos, "Tuberización in vitro de papa (Solanum tuberosum L), variedad Diacol Capiro, en biorreactores de inmersión temporal y evaluación de su comportamiento en campo", Ciencia, vol. 16(3), pp. 288-295, 2008.

[24] A. Aslam, and J. Iqbal, "Combined effect of cytokinin and sucrose on in vitro tuberization parameters of two cultivars i.e., diamant and red norland of potato (Solanum tuberosum)", Pak. J. Bot., vol. 42(2), pp. 1093-1102, 2010.

[25] A. Aslam, A. Ali, N. Huma, A. Saleem, and J. Iqbal "Effect of interaction of 6-benzyl aminopurine (BA) and sucrose for efficient microtuberization of two elite potato (Solanum tuberosum L.) cultivars, Desiree and Cardinal", $A J B$, vol. 10(59), pp. 1273812744, 2011.

[26] D. Donnelly, W. Coleman, and S. Coleman, "Potato microtuber production and performance", $A J P R$, vol. 80, pp. 103-115, 2003.

[27] M. Hoque, "In vitro tuberization in potato (Solanum tuberosum L.)", Plants Omics, vol. 3(1), pp. 7-11, 2010.

[28] J. Morales, Transformación genética de plantas de papa (Solanum tuberosum L.) con el gen que codifica para el inhibidor de cistein proteinasas de origen humano; cistatina C. Universidad de Colima, Facultad de Ciencias Biológicas y Agropecuarias, Colima, Estado de Colima, México, 2006.

[29] C. Fuentes, J. Rivera, C Sánchez, A. Cruz, R. Gutiérrez, y A. Valdez, "Producción in vitro de microtubérculos de papa cv. Alpha", Facultad de Ciencias Químico-Biológicas, Universidad Autónoma de Sinaloa, México. 2012. Disponible en: http://www. conpapa.org.mx/files/congress/2012/ technical_scientific/produccion_in_vitro_ microtuberculos_papa_cv_alpha.pdf.

[30] N. Coria, A. Pérez, J. Sarquís, I. Cantú, H. González, y M. Gómez, "Regeneración de la planta de papa (Solanum tuberosum L.) In vitro a partir del estolón", Ciencia UANL, vol. 7(3), pp. 361-370, 2004. 